American J. of Engineering and Applied Sciences 4 (1): 142-152, 2011

ISSN 1941-7020

(C) 2010 Science Publications

\title{
Evaluating Agility in Extended Enterprise Systems: A Transportation Network case
}

\author{
Mo Mansouri, Anirban Ganguly and Ali Mostashari \\ School of Systems and Enterprises, Babbio Building 5th Floor, \\ Stevens Institute of Technology, Hoboken, NJ 07030, USA
}

\begin{abstract}
Problem statement: Agility of an enterprise system is considered as its ability to adapt successfully and efficiently to unexpected changes of the environment. Agility is key in effectiveness of enterprise systems and also it is crucial in gaining competitive advantage in global market. Approach: This is particularly true in the case of an Extended Enterprise System (EES), which represents a network of interconnected enterprises. Infrastructure systems such as transportation systems are generally considered examples of an EES. Results: The efficiency of an EES generally lies in its responsiveness to the change and the ability of all its constituents in working effectively in order to achieve a common objective. As a result, agility might prove to be a very important ingredient for an EES to thrive and sustain in today's highly complex and interrelated environment. The purpose of this study is to introduce an assessment method and a subsequent agility index to evaluate agility in a generic EES and utilize it to a selected part of the New York City transportation network. The proposed method in this research is essential for understanding the nature and quality of interaction among constituent systems and provides stakeholders with the knowledge that is necessary for agility management in an EES. The contribution of this study to the domain of management and systems science are twofold. Firstly, the proposed method is expected to be a prominent part of the available literatures on evaluating the agility of an EES. Secondly, it is applied to a transportation network case, which as an infrastructure system is considered to be a classic example of an EES. Conclusion: Findings of such research will be useful in developing network agility strategies from the governance perspective.
\end{abstract}

Key words: Agility strategy, Extended Enterprise System (EES), agility index, evaluating agility

\section{INTRODUCTION}

In today's business environment, which is characterized by globalization and cutthroat competition, the ability to adapt to unexpected changes is a key to success for an enterprise. This idea of adapting to unforeseen changes has led to the evolution of one of the latest concepts in business strategies, which is referred to as agility. Agility can be defined as the ability to response for both proactive (strategizing to meet some new, but unforeseen future needs) and reactive (reacting to and correcting some unforeseen changes) environmental stimulants and opportunities (Dove, 2001; 2005a; 2005b). Agility is fast becoming a key business driver for all organizations as well as a crucial factor to a firm's ability to survive and thrive in uncertain and turbulent markets (Ganguly et al., 2009). Agility enables an enterprise to survive and prosper in a highly competitive business environment by reacting quickly and effectively to continually changing market that is driven by customer requirements (Gunasekaran, 1999). Furthermore, it helps an enterprise to successfully create strategic alliances and networks along with a proper leverage of personnel and information (Gunasekaran, 1999). Therefore, agility is considered to be a very important tool for an Extended Enterprise System (EES), which is a network of organizations that interact to exchange critical resources such as raw materials, labor, access to markets, specialized skills and knowledge (Tillquist, 2002), to achieve an overall objective.

The term "system" is defined as a: "set or arrangement of elements (people, products (hardware and software) and processes (facilities, equipment, material and procedures)) that are related and whose behavior satisfies customer/operational needs and provides for the life cycle sustainment of the products". Similarly, "enterprise" is described as a: "Goal-directed complex system of resources-human, information, financial and physical-and activities, usually of

Corresponding Author: Mo Mansouri, School of Systems and Enterprises, Stevens Institute of Technology, Castle Point on Hudson, Hoboken, NJ 07030, USA Tel: (201) 216-8844 
significant operational scope, complication, risk and duration" (Rouse, 2005). However, the necessities of today's market have pushed organizations to become extended network-based organisms that are able to operate in extremely complex environments. In order to capture the dynamic nature of such entities, we combined the existing approaches and definitions to introduce an EES as: "a complex network of distinctive yet distributed and interdependent organizational systems that are connected in an autonomic way to achieve objectives beyond reaching capacities of each" (Mansouri and Mostashari, 2010). The type of interactions among constituent systems of such a network might be defined based on: hierarchy, collaboration, coordination, or a combinatorial form (hybrid). However, regardless of the interconnectivity rules and forms, agility of an EES is crucial for survival in the market. In order to have an agile EES, it is necessary not only to have a network of agile constituents, but also to achieve a level of systemic agility through which the entire EES becomes responsive to the environmental changes.

The purpose of this study is to propose a method for evaluating the level of agility in an EES and subsequently to derive an agility index based on that. Starting with a review of the existing literature on organizational agility and EES, the study goes on to define a method of measurement, which will be useful in assessing the agility of an EES. The proposed methodology and the index are subsequently applied in an illustrative case study from the area of transportation. According to the definition of the term, infrastructure systems including transportation systems, large-scale and socio-technological systems and supply chains, are all examples of an EES. Although a subcategory within the area of transportation systems have been chosen as a case study in this research, similar approaches can be applied in other capacities to all infrastructure systems as well as other types of Extended Enterprise Systems. Finally, conclusions are drawn from the research results and direction of future research is provided.

\section{An overview of the theoretical concepts:}

An overview of enterprise agility: The concept of agility resulted from the idea of addressing the requirements of "post mass-production competitive environment" (Kettunen, 2009), where the old methods of manufacturing in large batches were no longer appropriate (Dove, 2004; Tsourveloudis and Valavanis, 2001). The agility of an organization lies in its ability to sense unforeseen changes in the business environment and respond readily to adapt to those changes (Overby et al., 2006). The idea of agility was initially developed by a group of researchers in 1991 at the Iacocca Institute, Lehigh University, in order to describe the practices that should be observed and considered as vital aspects of the manufacturing process (Yusuf et al., 1999). The proponents of agility at the Iacocca Institute defined agility as a manufacturing system with extraordinary capabilities to shift quickly among product models or product lines, ideally in real time, to meet the rapidly changing customer and business needs and requirements (Sherehiy et al., 2007).

An agile organization is therefore capable of operating effectively in a rapid and continually changing markets and business environment defined by customer designed products and services (Cho et al., 1996; Goldman et al., 1995) while having a near perfect balance among the four critical dimensions of manufacturing namely, time, cost, quality and scope (Dove, 2001). Agility aids an enterprise to thrive and prosper in an nonlinear, uncertain and unpredictable business environment (Kidd, 1997) through quickly and successfully producing low-cost, high-quality products that provide enhanced value to customers through customization (Fliedner and Vokurka, 1997). Furthermore, agility of an organization is not only a reactive phenomenon, but also can be proactive in nature (Dove, 2001). In other words, an agile enterprise not only reacts effectively to any sudden change in the business environment, but also proactively tries to assess any unforeseen changes in the customer and business requirements and strategizes action plans accordingly. As a result, an agile enterprise always stands a much better chance of growth than its nonagile counterpart.

A thorough review of various definitions of agility indicated that the common underlying thread among the definitions are time and cost. Additionally, also a set of peripheral attributes (like quality, being proactive and knowledge management) plays a pivotal role in determining the agility of an enterprise (or an EES). Therefore, it is worthwhile to include these attributes as a part of the working definition of agility in the context of this research, which is loosely based on the definitions by Yusuf et al. (1999), Dove (1999; 2001) and Ganguly et al., (2009) as is given as:

"The ability of an EES to integrate its response-ability and knowledge management in an effective and efficient way, in order to profitably and accurately adapt to any 
unexpected (or unpredictable) change in both proactive and reactive business or customer needs and opportunities in a rapid manner without compromising with the cost or the quality of the product or process"

The working definition of agility embeds within itself all the major characteristics of enterprise agility. These characteristics can also be extended to the agility of an EES. Therefore, it is imperative that this working definition and the key characteristics of agility are kept in mind while determining the set of metrics that would provide an EES to evaluate its agility.

One of the key aspects of being successfully agile is the ability of an enterprise to share resources and technologies among companies (Sanchez and Nagi, 2001). The competitiveness of an enterprise depends on its ability to establish proper relationships, in the form of an internal cross-functional team with participation from suppliers and customers, in order to yield the greatest competitive advantage in the market (Sanchez and Nagi, 2001). This is especially true for an EES, where a group of independent entities interact with other to achieve a common objective. However, there is still a dearth of academic and industrial literature related to evaluating the agility of an EES, something that this present research hopes to shed some light on.

Efforts in measuring agility: Proper evaluation and measurement of agility is a required component in the process of strategic planning in an enterprise. It enables an enterprise to determine its level of agility (or the collective level of agility, in the case of an EES). Understanding the level of agility can be used in assessing the planning gap and thus formulating a strategy to bridge it. The necessity for suitable performance measurements as well as quantitative analysis methodologies in order to determine the agility of a system has been pointed out in the literature (Gunasekaran, 1999). However, there does not exist a direct, adaptive and holistic treatment of agility components (Tsourveloudis and Valavanis, 2001). Various researchers, over the years, have put forward various theories and techniques on measurement and evaluation of enterprise agility.

One of the earliest discussions on the measurement of agility has been published in Production in which a set of change proficiency metrics including cost, time, quality and scope are developed that can be used to measure the overall agility of an enterprise (Dove, 2001). The concept of change proficiency was further developed in another research (Metes et al., 1998) with a framework that involved designing a six-step methodology using a balanced scorecard to assess different domains of agility (Arteta and Giachetti, 2004). Other approaches to measuring the agility of an enterprise are including but not limited to: the Agility Index (AI) (Kumar and Motwani, 1999); Goranson (1999) model of agile virtual enterprise Hoek et al. (2001) scorecard; the Agility Measurement Index (AMI) (Datta, 2006); the Fuzzy Agility Evaluation Method (FAEM) (Lin et al., 2006; Yang and Li, 2002); the Fuzzy QFD approach (Bottani, 2009); the multi criteria approach of AHP; Bayesian Belief Networks (Yu and Heng, 2006) and the fuzzy logic approach (Tsourveloudis and Valavanis, 2001).

The present research concentrates on proposing an assessment technique for evaluating the agility of an extended enterprise system, rather than a single manufacturing (or service) enterprise. The proposed methodology is equally applicable to EES pertaining to both the manufacturing as well as the service sector since it provides a general framework of evaluating agility, rather than targeting any specific EES.

Extended enterprise systems: Enterprises must develop strategies that enable them to identify the key internal and external influences, which empowers their competitiveness or make them vulnerable to foreseen or unforeseen circumstance. While both external and internal influences are products of business dynamics and known to be beyond an enterprise's control, they can often be adapted to within a changing environment. Therefore, it is very important for enterprises to achieve the ability of rapidly changing processes to satisfy emerging business needs through reconfiguration of structures and redefinition of their directions. The crucial need for modifying the structure of an enterprise to align its business with appropriate technology and the vital necessity for being prepared to access resources with limited information while rapidly changing processes to satisfy emerging demands, have brought about new kinds of organizational structures.

Such enterprises are developed based on interaction with other organizations through sharing of information and resources within and across their boundaries. As a result, a shift from disintegrated and centralized enterprise structures to more integrated, open and collaborative enterprise structures is required (Tan et al., 2006). These kinds of enterprise structures are frequently referred to as "Extended Enterprises (EE)," virtual enterprises, or supply chains. However, the interconnections among enterprises create an integrated system that enables the application of a systemic approach to this matter. The term "Extended Enterprise System (EES)" is used for referring to this 


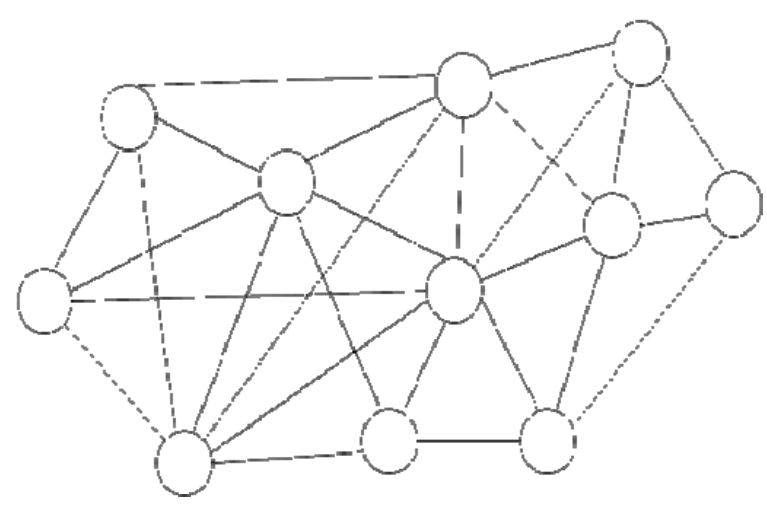

Fig. 1: The structure of an EES

concept; moreover, "constituent systems" or "constituencies" are used for addressing enterprises within an EES.

The structure of an EES provides opportunities to increase the level of interactions, which enhances the ability for constituent systems to respond rapidly to changing business opportunities. However, the complexities caused by the increased level of interrelationships and interdependencies can also introduce new threats to the system (Fiksel, 2007). As the constituent enterprises are required to redesign their processes, operationsand systems, they are also required to have a better understanding about those of their partners. Therefore, there is a need for developing a new level of knowledge to be shared in a higher level of abstraction known as "System of Systems (SoS)".

There have been several attempts to define SoS. However, there is not such a consensus in referring to the meaning of this term and a universally accepted definition is yet to be presented (Sage and Cuppan, 2001). Some explained SoS from a structural perspective (Luskasik, 1998; Manthorpe, 1996) and others defined it by its characteristics (Maier, 1998; Bar-Yam, 2004; DeLaurentis, 2005; Boardman and Sauser, 2006). In a similar way extended enterprise is referred to as "a wider system of enterprises" (Boardman and Sauser, 2008) that represents the holistic concept of enterprises alongside its internal components and external connectors including business partners, suppliers and customers (Slade and Bokma, 2002). From the same holistic perspective, an extended enterprise integrates all its processes, applications, people and knowledge in pursuit of higher efficiency and effectiveness (Markus, 2000; Kosanke et al., 1999). Regardless of the terms being used and their definitions such network-oriented structures have emerged from the complexity of global interrelations and as a response to the need for globalization of markets (GoldBernstein and Ruh, 2004; Pinkston, 2001).

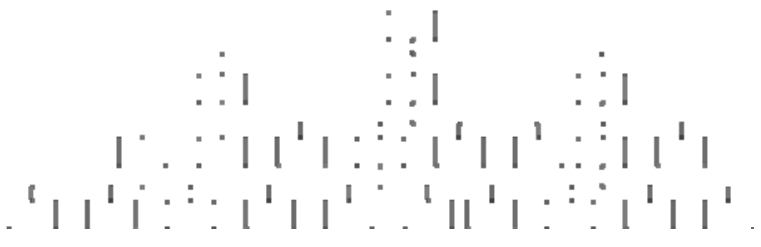

Fig. 2: The Structure of constituent systems of an EES

Figure 1 depicts structure of an Extended Enterprise System as a network of enterprises that defines the environment of an extended enterprise in a SoS level. The constituent systems of EES are each an enterprise whose structure is shown in Fig. 2, schematically. Combination of the two structures makes a complex entity of interrelationships that requires a specific approach for formulating the problem and answering new set of research questions. This study is an attempt to define and evaluate agility as a required characteristic of EES.

\section{MATERIALS AND METHODS}

Research model: As depicted in Fig. 1 and 2, each of the nodes of an EES are by themselves a system that functions independently to achieve an overall objective. Therefore, a proper interaction among the nodes of an EES plays a vital role in its success. Being agile, therefore, can serve as a vital factor in increasing the level of interactions among the nodes. However, the complex structure of an EES makes it difficult to assess its agility. The primary focus of this research is to shed some light on this issue by proposing a set of quantifiable metrics that would be helpful in evaluating the agility of an EES. Before moving on to a more detailed discussion on the metrics and applied methodology used to develop them, it will be useful to show a simple conceptual model of agility as related to this research. What exhibited in Fig. 3 provides readers with a better understanding of the research model we used in this study as well as the importance of the agility metrics.

Figure 3 shows the basic research model and its associated stages. The need for an enterprise (or an EES) to be agile is to adapt to changes in the business environment. This sudden change in the business environment is governed by a set of factors called Agility Drivers $\left(\mathrm{AD}_{\mathrm{n}}\right.$ in Fig. 3). Agility drivers can be stated as the factors that compel any organization to revisit and revise their existing business model, thereby necessitating an organization to adopt an agility strategy (Sherehiy et al., 2007; Sharifi and Zhang, 1999) in order to maintain their competitive advantage 


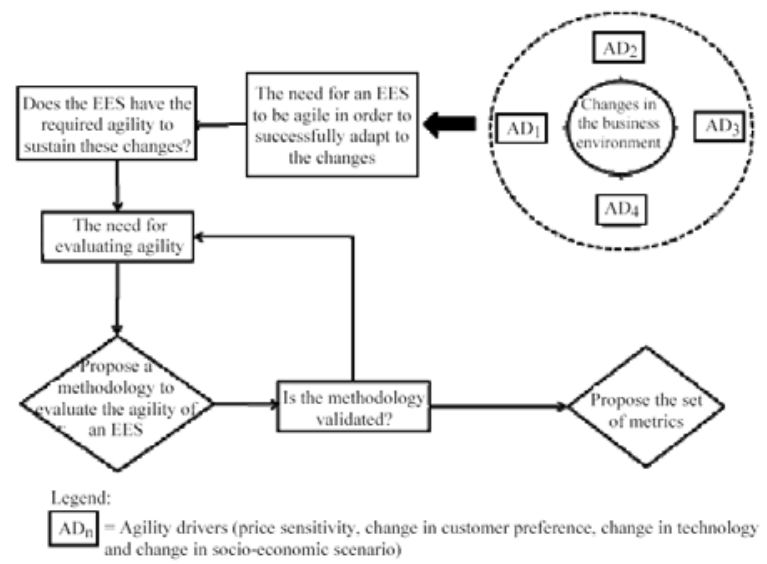

Fig. 1: The basic research model

in the market. The purpose of any agility driver is to compel an organization to exploit the changes in the market, in order to gain an advantage over its competitors through the design and implementation of an agility strategy (Ganguly et al., 2009).

However, the absence of a proper evaluation methodology makes it difficult for an EES to identify and assess their agility capabilities and design a strategic plan accordingly. Therefore, the development of an assessment methodology (and subsequently, an agile index) will play a pivotal role in agility evaluation process for an EES. Once the proposed methodology is developed, the next stage will be to validate it using an illustrative case analysis. The illustrative case study for this research is chosen from transportation systems and the proposed metrics are validated using the case study. Conclusions are drawn based on the findings of the research.

Research methodology: In order to develop quantifiable metrics for evaluating agility in an EES, we use a mathematical function that calculates the summation of the weighted agility factors associated with each constituent system within a network. The idea is to consider agility of the entire network as a function of some important performance attributes of its constituent systems and the objective is to use mathematical optimization methods to find an optimum solution for such an indicative function, which we call Total Agility Index (TAI). Selecting the agility drivers for each constituent system has obviously a crucial role in formulating such an index. Therefore, the optimum solution for the problem varies based on the subjective selection of agility factors. Although concepts such as service level or quality as well as reliability or security have been also considered among agility factors within enterprises, qualitative nature of such factors limits the practicality of optimization and thus reduces its accuracy.

Considering the level of complexity, which is created in a network as a result of interconnections among constituent systems, we suggest focusing on two major factors of time and cost in formulating agility in an EES. Time factor might be included in formulation through calculating any given attribute of time in each constituent system that can be an effective representative of change within the environment. The aforementioned attributes of time might be: average time of performance or service delivery that can be used to calculate the minimum or maximum time to response or adapt within a network.

"Time to response" refers to the delay between the point on time dimension that system receives an imposing change and the point it reacts and responses to the received pulse. However, "time to adapt" captures the delay between shock and returning back to normalcy after dealing with it. Choosing these factors depends on what the decision-makers want to stress upon or take into consideration. The same is true about choosing "average", "maximum", or "minimum" of these factors for each constituency, as each one of these attributes stress on a different part of agility in the entire system.

A very similar approach is suggested in regards to including "cost" in our agility optimization method. Several attributes of cost such as average, minimum, or maximum costs for response or recovery in each enterprise system, can be included in the formulation of agility as well. Another approach might be to see cost as a function of time and exclude that from formulation of TAI. It is an acceptable argument for many cases in which cost of the system is more closely related with time. Quite similarly, it is common to interpret all time related measures into cost values. It is usually a way to have a better understanding about the space of decisionmaking and consequently making more effective and efficient decisions. In general, there is a correlation between time and cost in systems; however, sometimes their relationship is not linear. Moreover, the decisionmakers in a system or the body of stakeholders in a network might want to weigh these factors differently to emphasize on different aspects of agility.

Another important part of formulation is weighing agility factors in TAI formulation. These weights are usually defined subjectively and by decision-makers in a system level or stakeholders in a network level. The purpose of weighing is to set priorities for factors that have been included in TAI formulation, mathematically. This will enable emphasizing on 
Am. J. Engg. \& Applied Sci., 4 (1): 142-152, 2011

different aspects of agility within the entire network through projection of its importance for each one of the constituent systems. In addition to defining weights subjectively, it is also possible to set them mathematically by taking the contribution of each system to the entire network into account for calculation. We take a similar approach in our case study.

Equation 1 is the suggested function for formulating Total Agility Index in network of systems in which $\mathrm{a}_{\mathrm{i}}$ is the agility factor for $\mathrm{i}^{\text {th }}$ constituent system and $\mathrm{w}_{\mathrm{i}}$ refers to its associated weight. It is important to know that both $a_{i}$ and $w_{i}$ can also be calculated as a combined factor of several attributes such as time, cost, quality, reliability; or capacity, usage, share of contribution to the network, respectively. Moreover, N is the number of constituent systems in the network. After formulation of such problem the objective will be to optimize the TAI function by making policies on changing capacities in transportation channels to achieve the best flow or minimizing average cost as well as average time to response:

$$
\mathrm{TAI}=\sum_{\mathrm{i}=1}^{\mathrm{N}} \mathrm{w}_{\mathrm{i}} \mathrm{a}_{\mathrm{i}}{ }^{2}
$$

Table 1 presents the structure of our suggested approach in a tabular format in which columns are assigned to agility factors as well as weights while rows contain constituent systems. Subsequently, we will adopt the same approach to formulate the Total Agility Index for the network of transportation connections within and to the City of New York.

In the next step, we will take a major part of New York City transportation network and use the abovementioned approach to calculate Total Agility Index for that network. In this case study, we will consider Average Travel Time, Average Delay Time and Average Travel Cost as the important measurable attributes of constituent systems and adopt the share of service that is the number of people who use the system as a way of weighting the combined agility drivers. In another step, we will transform the time related attributes into cost values and present a cost-based TAI for the transportation network of New York City. The newly defined index can be used as a tool for evaluation of agility in that particular transportation network.

Evaluating agility in transportation network of New York city: New York City (NYC) transportation system contains several distinctive yet interdependent systems that connect adjacent cities in the State of New
Table 1: A tabular format of the suggested approach for calculating total agility index

Cons-tituent Ave. Ave. Agility Share of Weight

Sys. Time Cost factor $\left(a_{i}\right)$ Cap-acity usage factor

$\left(\mathrm{w}_{\mathrm{i}}\right)$

Sys 1

Sys. i

Sys. N

Jersey (NJ) and the boroughs of the State of New York (NY). The Metropolitan Transportation Authority (MTA) mostly serves southeastern counties of NY by carrying over 11 million passengers on an average weekday all across its territory. The MTA is a public benefit corporation, which is responsible for public transportation and for developing and implementing a unified mass transportation policy for NY metropolitan area, including all five boroughs of NYC, several counties of NJ and a couple of counties in Connecticut (CT). In addition to the MTA, there are other connectors between NY and NJ including Path, NJ Transit Train, busses and shuttles as well as boats and ferries (Metropolitan Transportation Authority, 2010).

The collection of all these connectors that work independently and under distinctive organizational system makes a large network that can be considered as an EES. Although operational optimization at each one of these entities will improve performance of the entire network, the most effective way to achieve such a goal is to have a systemic approach to the problem. Agility as an attribute of performance is an example, which based on the suggested approach in this research, must be considered in a holistic way and within the context of the entire extended enterprise system of transportation in NYC. Consequently, this case is used to demonstrate how agility should be calculated and evaluated in an EES.

As for defining the NYC transportation network's environment, we focus our research on four major constituent system of: Subway, Bus, Long Island Rail Road (LIRR) and Metro-North Railroad (MNR). The other prominent constituents of MTA network that connects NYC to New Jersey via tunnels and bridges are being studied in our other research activities and from the perspective of resilience of the traffic system. The reason for excluding those constituents of the system is that traffic related side of this problem, where other means of transportation including automobiles, shuttles and ferries must be considered, are different with the services delivered by MTA in nature. Combining the two problems could be another extension to this research that can cover the multilayered problem of the large transportation network of NYC. We will address this level of formulation in our future researches. 
Am. J. Engg. \& Applied Sci., 4 (1): 142-152, 2011

As for formulation of the problem, we consider Average Travel Time, Average Delay Time and Average Travel Cost as the important measurable attributes, hence the main agility factors of constituent systems. We also adopt a weighing method based on the usage in which each system of transportation is weighed proportionate to its share of usage in the entire system. The Total Agility Index for the normal status of the entire system will be developed based on summation of squared weighted agility factors for each transportation system. The cost factor has been included in formulation of the problem both directly and indirectly. Average travel cost for each system takes the direct cost of transactions into account. Moreover, time related factors are indirectly monetized in order to transform all considerations into one dimension. However, while there are resources available for estimation of time related factors, there is none to describe the costs associated with traffic in case of congestion or other major disturbances. Therefore, we have estimated these costs based on average income of people in NYC greater area.

Table 2 shows the information we excerpt from MTA website and use to formulate the problem and evaluate current status of the network regarding agility (Metropolitan Transportation Authority, 2010). The average time of service column in this table reflects the upper bound of the available data for each category of systems.

To use Eq. 1 effectively, first, we need to calculate the combined agility factor. We do this calculation based on transforming all time related agility factors to cost values, which we call Average Value Cost (AVC). This will be possible by summation of Average Travel Time (ATT) and Average Delay Time (ADT), times the Average Opportunity Lost (AOL), which is the average hourly income of passengers. This cost based value will be added to the Average Travel Cost (ATC) and gives us the combined agility driver for each constituent system. Using the combined agility drivers we will be able to calculate Total Agility Index as exhibited subsequently. Equation 2 and 3 in the following represent the steps applied to define TAI for the transportation network of NYC:

$$
\mathrm{TAI}=\sum_{\mathrm{i}=1}^{\mathrm{s}} \mathrm{w}_{\mathrm{i}} \mathrm{a}_{\mathrm{i}} \mathrm{AVC}=[(\mathrm{ATT}+\mathrm{ADT}) / 60] * \mathrm{AOL}
$$

Considering a hypothetical amount of $\$ 20$ per $h$ as the Average Opportunity Lost (AOL) for MTA passengers, we can calculate the combined agility driver for each constituent system. The results of this calculation are presented in Table 3.
Table 2: Agility factors and usage weights for constituent systems of the transportation network of NYC

\begin{tabular}{llllll}
\hline $\begin{array}{l}\text { Trans. sys. } \\
\left(\mathrm{S}_{\mathrm{i}}\right)\end{array}$ & $\begin{array}{l}\text { Ave. travel } \\
\text { time } \\
\left(\mathrm{a}_{1}\right) \text {-min }\end{array}$ & $\begin{array}{l}\text { Ave. delay } \\
\text { time } \\
\left(\mathrm{a}_{2}\right)-\min \end{array}$ & $\begin{array}{l}\text { Ave. travel } \\
\text { cost } \\
\left(\mathrm{a}_{3}\right)-\mathrm{USD}\end{array}$ & $\begin{array}{l}\text { Ave. } \\
\text { weekday } \\
\text { passenger }\left(\mathrm{u}_{\mathrm{i}}\right)\end{array}$ & $\begin{array}{l}\text { Weights } \\
\left(\mathrm{w}_{\mathrm{i}}=\mathrm{u}_{\mathrm{i}} / \sum \mathrm{u}_{\mathrm{i}}\right)\end{array}$ \\
\hline $\mathrm{S}_{1}=$ Metro & 45 & 15 & 2.25 & 7,626264 & 0.9160 \\
$\mathrm{~S}_{2}=\mathrm{LIRR}$ & $100^{2}$ & 15 & $15.50^{3}$ & 302,583 & 0.0363 \\
$\mathrm{~S}_{3}=$ MNR & $65^{4}$ & 15 & $15.50^{5}$ & 287,119 & 0.0345 \\
$\mathrm{~S}_{4}=$ Bus & 60 & 20 & 3.90 & 109,729 & 0.0132 \\
\hline
\end{tabular}

${ }^{2}$ : The longest time is $3 \mathrm{~h}$ (from Penn station to Montauk) and the shortest time is around 15-20 min. Therefore, we used $100 \mathrm{~min}$ as the average travel time; ${ }^{3}$ : Minimum fare for using LIRR is $\$ 8.00$ and maximum fare is $\$ 23.00$ during weekdays. Therefore, we chose $\$ 15.50$ to be the average cost; ${ }^{4}$ : The longest travel time is around $120 \mathrm{~min}$ and the shortest is around $10 \mathrm{~min}$. Therefore, we chose $65 \mathrm{~min}$ as the average travel time; ${ }^{5}$ : Since the highest fare on MNR is $\$ 25.00$ and the lowest is $\$ 6.25$, we used $\$ 15.50$ to be the average cost

Table 3: Combined Agility factors for constituent systems of the transportation network of NYC

\begin{tabular}{lcllll}
\hline $\begin{array}{l}\text { Trans. Sys. } \\
\left(\mathrm{S}_{\mathrm{i}}\right)\end{array}$ & $\begin{array}{l}\text { ATT } \\
\left(\mathrm{a}_{1}\right) \text {-min }\end{array}$ & $\begin{array}{l}\text { ADT } \\
\left(\mathrm{a}_{2}\right) \text {-min }\end{array}$ & $\begin{array}{l}\text { AOL- } \\
\text { USD }\end{array}$ & $\begin{array}{l}\text { Agility } \\
\text { factor-USD }\end{array}$ & $\begin{array}{l}\text { Weights } \\
\left(\mathrm{w}_{\mathrm{i}}=\mathrm{u}_{\mathrm{i}} / \sum \mathrm{u}_{\mathrm{i}}\right)\end{array}$ \\
\hline $\mathrm{S}_{1}=$ Metro & 45 & 15 & 20 & 20.00 & 0.9160 \\
$\mathrm{~S}_{2}=$ LIRR & 100 & 15 & 20 & 38.33 & 0.0363 \\
$\mathrm{~S}_{3}=$ MNR & 65 & 15 & 20 & 26.67 & 0.0345 \\
$\mathrm{~S}_{4}=$ BuS & 60 & 20 & 20 & 26.67 & 0.0132 \\
\hline
\end{tabular}

Having the combined agility factors for each system, we can use Eq. 3 to calculate Total Agility Index for the entire network as is shown below:

$$
\begin{aligned}
\mathrm{TAI}_{\text {Baseline }} & =\sum_{\mathrm{i}=1}^{4} \mathrm{w}_{\mathrm{i}} \mathrm{a}_{\mathrm{i}}{ }^{2}=57.2640=0.9160(20.00)^{2} \\
& +0.0363(38.33)^{2}+0.0345(26.67)^{2} \\
& +0.0132(26.67)^{2}=453.66
\end{aligned}
$$

\section{RESULTS AND DISCUSSION}

We consider the calculated TAI as an index that sets a base for the level of agility in the network, when everything is normal and the system is not disturbed by any shock nor faces any adversity. Hence, we name it TAI-Baseline. Such an index (baseline) can be used as a tool for benchmarking and thus, evaluating the agility of transportation network in NYC, while faced a major change. In case that a general monitoring system is following the status of such system; the stakeholders of NYC transportation network will be able to estimate changes in agility factors that is reflected mostly via fluctuation of the average time of service (including travel time and delays) as well as possible changes in usage of each transportation system either in a probabilistic or deterministic way. Consequently, insertion of such information into Eq. 2 will give the stakeholders and idea about how agility of their entire network is changing due to the changes in environment. This is exhibited in the expression that forms Eq. 3. 
Am. J. Engg. \& Applied Sci., 4 (1): 142-152, 2011

Therefore, the above-mentioned suggested approach for formulating agility can be applied as a tool for quantification, measurement and as a result, optimization in NYC transportation network. In the following, we describe several different scenarios that affect the attributes of the constituent systems. Based on the proposed characteristics, Eq. 2 and 3 will be adopted to recalculate TAI for each presented scenarios. Comparison of these calculated TAIs enables stakeholders or decision-maker of the NYC transportation network to understand the nature of agility in a network level.

Scenario 1: The dynamics of transportation in NYC is affected by an event such as a parade in Midtown or a baseball game at Yankee's Stadium that has affected only the average delay times for the subway system, increasing it and average of $10 \mathrm{~min}$ for subway and bus. The assumption is that the average travel time remains the same for all the constituent systems. Moreover, consequent changes in attributes of other constituent systems that might be caused by delays in subway and bus systems are excluded. Table 4 presents changes in average delay time for the selected constituent systems of subway and bus in Scenario 1.

The following present the calculation of TAI for Scenario1:

$$
\begin{aligned}
\mathrm{TAI}_{\text {Scenariol }} & =\sum_{\mathrm{i}=1}^{4} \mathrm{w}_{\mathrm{i}} \mathrm{a}_{\mathrm{i}}^{2}=57.2640=0.9160(23.33)^{2} \\
& +0.0363(38.33)^{2}+0.0345(26.67)^{2} \\
& +0.0132(30.00)^{2}=588.47
\end{aligned}
$$

Scenario 2: The long island rail road system is down because of an unexpected accident on the line and has increased the average delay times by $15 \mathrm{~min}$ and the average travel time by $10 \mathrm{~min}$ in that system. Again, consequent changes in attributes of other constituent systems are assumed not affected. Table 5 presents changes in average travel and delay time for the selected constituent systems of LIRR in Scenario 2.

The following present the calculation of TAI for Scenario 2:

$$
\begin{aligned}
\mathrm{TAI}_{\text {Scenario2 }} & =\sum_{\mathrm{i}=1}^{4} \mathrm{w}_{\mathrm{i}} \mathrm{a}_{\mathrm{i}}{ }^{2}=57.2640=0.9160(23.33)^{2} \\
& +0.0363(46.67)^{2}+0.0345(26.67)^{2} \\
& +0.0132(26.67)^{2}=611.68
\end{aligned}
$$

Scenario 3: The Metro-North Railroad system causes an average of 10 min delay time because of a technical issue on the line. Supposing this issue does not incur any consequences for other constituent systems, the new characteristics of the network are presented in Table 6.
Table 4: The affected attributes and combined agility factors of constituent systems-Scenario 1

\begin{tabular}{lcllll}
\hline $\begin{array}{l}\text { Trans. Sys. } \\
\left(\mathrm{S}_{\mathrm{i}}\right)\end{array}$ & $\begin{array}{l}\text { ATT } \\
\left(\mathrm{a}_{1}\right) \text {-min }\end{array}$ & $\begin{array}{l}\text { ADT } \\
\left(\mathrm{a}_{2}\right) \text {-min }\end{array}$ & $\begin{array}{l}\text { AOL- } \\
\text { USD }\end{array}$ & $\begin{array}{l}\text { Agility } \\
\text { factor-USD }\end{array}$ & $\begin{array}{l}\text { Weights } \\
\left(\mathrm{w}_{\mathrm{i}}=\mathrm{u}_{\mathrm{i}} / \sum \mathrm{u}_{\mathrm{i}}\right)\end{array}$ \\
\hline $\mathrm{S}_{1}=$ Metro & 45 & 25 & 20 & 23.33 & 0.9160 \\
$\mathrm{~S}_{2}=\mathrm{LIRR}$ & 100 & 15 & 20 & 38.33 & 0.0363 \\
$\mathrm{~S}_{3}=$ MNR & 65 & 15 & 20 & 26.67 & 0.0345 \\
$\mathrm{~S}_{4}=$ Bus & 60 & 30 & 20 & 30.00 & 0.0132 \\
\hline
\end{tabular}

Table 5: The affected attributes and combined agility factors of constituent systems-Scenario 2

\begin{tabular}{llllll}
\hline $\begin{array}{l}\text { Trans. Sys. } \\
\left(\mathrm{S}_{\mathrm{i}}\right)\end{array}$ & $\begin{array}{l}\text { ATT } \\
\left(\mathrm{a}_{1}\right) \text {-min }\end{array}$ & $\begin{array}{l}\text { ADT } \\
\left(\mathrm{a}_{2}\right) \text {-min }\end{array}$ & $\begin{array}{l}\text { AOL- } \\
\text { USD }\end{array}$ & $\begin{array}{l}\text { Agility } \\
\text { factor-USD }\end{array}$ & $\begin{array}{l}\text { Weights } \\
\left(\mathrm{w}_{\mathrm{i}}=\mathrm{u}_{\mathrm{i}} / \sum \mathrm{u}_{\mathrm{i}}\right)\end{array}$ \\
\hline $\mathrm{S}_{1}=$ Metro & 45 & 15 & 20 & 23.33 & 0.9160 \\
$\mathrm{~S}_{2}=$ LIRR & 110 & 30 & 20 & 46.67 & 0.0363 \\
$\mathrm{~S}_{3}=$ MNR & 65 & 15 & 20 & 26.67 & 0.0345 \\
$\mathrm{~S}_{4}=$ Bus & 60 & 20 & 20 & 26.67 & 0.0132 \\
\hline
\end{tabular}

Table 6: The affected attributes and combined agility factors of constituent systems-Scenario 3

\begin{tabular}{lcllll}
\hline $\begin{array}{l}\text { Trans. Sys. } \\
\left(\mathrm{S}_{\mathrm{i}}\right)\end{array}$ & $\begin{array}{l}\text { ATT } \\
\left(\mathrm{a}_{1}\right) \text {-min }\end{array}$ & $\begin{array}{l}\text { ADT } \\
\left(\mathrm{a}_{2}\right) \text {-min }\end{array}$ & $\begin{array}{l}\text { AOL- } \\
\text { USD }\end{array}$ & $\begin{array}{l}\text { Agility } \\
\text { factor-USD }\end{array}$ & $\begin{array}{l}\text { Weights } \\
\left(\mathrm{w}_{\mathrm{i}}=\mathrm{u}_{\mathrm{i}} / \sum \mathrm{u}_{\mathrm{i}}\right)\end{array}$ \\
\hline $\mathrm{S}_{1}=$ Metro & 45 & 15 & 20 & 20.00 & 0.9160 \\
$\mathrm{~S}_{2}=$ LIRR & 100 & 15 & 20 & 38.33 & 0.0363 \\
$\mathrm{~S}_{3}=$ MNR & 65 & 25 & 20 & 30.00 & 0.0345 \\
$\mathrm{~S}_{4}=$ Bus & 60 & 20 & 20 & 26.67 & 0.0132 \\
\hline
\end{tabular}

The following present the calculation of TAI for Scenario 3:

$$
\begin{aligned}
\mathrm{TAI}_{\text {Scenario3 }} & =\sum_{\mathrm{i}=1}^{4} \mathrm{~W}_{\mathrm{i}} \mathrm{a}_{\mathrm{i}}{ }^{2}=57.2640=0.9160(20.00)^{2} \\
& +0.0363(38.33)^{2}+0.0345(30.00)^{2} \\
& +0.0132(26.67)^{2}=460.18
\end{aligned}
$$

Evidently, minor changes in attributes of MNR do not affect the agility of the entire network as changes in subway system would. This is obviously because of relatively smaller weight in the formulation of TAI.

Scenario 4: The Bus system is affected by an accident in the city during rush hour, which causes an average of $15 \mathrm{~min}$ in travel time and an average of 15 min delay time. The effect of this single problem in transportation network is shown in Table 7.

The following present the calculation of TAI for Scenario 4:

$$
\begin{aligned}
\mathrm{TAI}_{\text {Scenario4 }} & =\sum_{\mathrm{i}=1}^{4} \mathrm{~W}_{\mathrm{i}} \mathrm{a}_{\mathrm{i}}{ }^{2}=0.9160(20.00)^{2} \\
& +0.0363(38.33)^{2}+0.0345(26.67)^{2} \\
& +0.0132(45)^{2}=471.00
\end{aligned}
$$

Now, looking back to the TAI-Baseline of the network, we can better understand the nature of agility in NYC Transportation network. We also calculate the 
Am. J. Engg. \& Applied Sci., 4 (1): 142-152, 2011

Table 7: The affected attributes and combined agility factors of constituent systems-Scenario 4

\begin{tabular}{lrllll}
\hline $\begin{array}{l}\text { Trans. Sys. } \\
\left(\mathrm{S}_{\mathrm{i}}\right)\end{array}$ & $\begin{array}{l}\text { ATT } \\
\left(\mathrm{a}_{1}\right) \text {-min }\end{array}$ & $\begin{array}{l}\text { ADT } \\
\left(\mathrm{a}_{2}\right) \text {-min }\end{array}$ & $\begin{array}{l}\text { AOL- } \\
\text { USD }\end{array}$ & $\begin{array}{l}\text { Agility } \\
\text { factor-USD }\end{array}$ & $\begin{array}{l}\text { Weights } \\
\left(\mathrm{w}_{\mathrm{i}}=\mathrm{u}_{\mathrm{i}} / \sum \mathrm{u}_{\mathrm{i}}\right)\end{array}$ \\
\hline $\mathrm{S}_{1}=$ Metro & 45 & 15 & 20 & 20.00 & 0.9160 \\
$\mathrm{~S}_{2}=$ LIRR & 100 & 15 & 20 & 38.33 & 0.0363 \\
$\mathrm{~S}_{3}=$ MNR & 65 & 15 & 20 & 26.67 & 0.0345 \\
$\mathrm{~S}_{4}=$ Bus & 100 & 35 & 20 & 45.00 & 0.0132 \\
\hline
\end{tabular}

Table 1: Scenario agility level

\begin{tabular}{lllc}
\hline Scenario & TAI-scenario & TAI-baseline & SAL $(\%)$ \\
\hline Scenario 1 & 588.47 & 453.66 & 29.71 \\
Scenario 2 & 611.68 & 453.66 & 34.83 \\
Scenario 3 & 460.18 & 453.66 & 1.44 \\
Scenario 4 & 471.00 & 453.66 & 3.82 \\
\hline
\end{tabular}

agility level of each scenario, called as Scenario Agility Level (SAL) as suggested in Eq. 8 below:

$\mathrm{SAL}_{\mathrm{i}}=\left(\frac{\mathrm{TAI}_{\text {Scenario }_{\mathrm{i}}}-\mathrm{TAI}_{\text {Baseline }}}{\mathrm{TAI}_{\text {Baseline }}}\right) * 100$

The results of Scenario Agility Level calculations for each scenario is summarized in Table 8 in the following:

Looking at the Scenario Agility Level percentages shows that the NYC transportation network as described in Scenario 1 is $29.71 \%$ less agile from the baseline, while Scenario 2 makes the network $34.83 \%$ less agile. These are 1.44 and $3.82 \%$ for Scenario 3 and 4 respectively. Taking these calculations into account, stakeholders of the network can make strategic decisions for investments on infrastructure based on their understanding of the network's agility and according to the sensitivity of each constituent system regarding this matter.

The proposed method of this study can be applied in a more detailed approach through inclusion of all other constituent systems of the network or by increasing the number of systems' attributes that have an effect on the entire network's agility. Any of these extensions can be the subject of further research in the future.

\section{CONCLUSION}

As an important property of a system, agility is essential in survival of enterprises in the fast-paced environment of today's business. Agility is defined as the ability of a system to adapt to unexpected changes of business environment in an effective and efficient way. The concept has been discussed and quantitative methods been developed within the context of enterprise systems. However, modern enterprises are mostly developed based on a dynamic interaction with other organizations through sharing information and resources within and across their boundaries. This provides circumstances that require a modern type of structure that is developed in a format of a network. These new structures are referred to as Extended Enterprise Systems, System of Systems and organizational networks.

In this study, a summary of available definitions on agility for both enterprise and extended enterprise level were presented. The characteristics of EES in a SoS level were defined and considered within the context of networks. Understanding the characteristics of such extended structures reveals the necessity of redefining the properties of systems. In order to redefine the meaning of agility for EES and network-based environments, a research model that adopts the concept of Agility Drivers for individual systems were presented. The methodology is developed based on integration of agility factors for each constituent system within a network into a new level of quantification, which was termed as Total Agility Index (TAI).

The main characteristic of such an integrated Total Agility Index (TAI) is that it includes not only the agility drivers of each constituent system, but also it applies a weighing technique to prioritize the importance of these agility factors in formulation of agility for the entire network. Moreover, both agility drivers and agility weights can be the result of calculations that combine several factors and integrate them into one. Therefore, adopting the TAI approach for formulating agility in a network enables its stakeholders to include all the possible factors that might have an effect on performance of the network. This will provide them with opportunities to quantify, measure and optimize agility in the network.

The network of transportation in metropolitan area of New York City was considered as a case for presenting the aforementioned approach. The result was formulation of TAI according to the available estimations of usage or average time of service, including travel and delay time, within the transportation network. The calculated TAI represents the initial status of the network in regards to agility that is called the "Baseline" in this study. A better understanding on other influential factors in agility of each constituent transportation system will help us to define such initial status of the network more accurately. Moreover, it can be used as a benchmarking tool to evaluate the agility of the entire network in comparison to the past as well as a mathematical tool to optimize performance of the network in response to major disturbances. We presented four different 
scenarios to show how the attributes of each constituent system can be affected as a result of incidents or technical issues. Total Agility Indexes were calculated for each scenario based on which the concept of Scenario Agility Level was introduced that explains how changes in environment decreases agility of the entire network.

We believe that other networks or extended enterprise systems can adopt a similar approach and methodology to provide the stakeholders or decisionmakers with a tool for defining, measuring and optimizing agility in a System of Systems level. Such extensions to the problem presented in this study will be the subject of future researches.

\section{REFERENCES}

Arteta, B.M. and R.E. Giachetti, 2004. A measure of agility as the complexity of the enterprise system. Robot. Comput. Integ. Manuf., 20: 495-503. DOI: 10.1016/j.rcim.2004.05.008

Bar-Yam, Y., 2004. The characteristics and emerging behaviors system of systems. NECSI: Complex Physical, Biological and Social Systems Project. http://www.necsi.edu/education/oneweek/winter05/ NECSISoS.pdf

Boardman, J. and B. Sauser, 2006. System of systems the meaning of of. Proceedings of the IEEE International Conference on System of Systems Engineering, Apr. 24-26, Los Angeles, CA., pp: 6-6. DOI: 10.1109/SYSOSE.2006.1652284

Boardman, J. and B. Sauser, 2008. Systems Thinking: Coping with 21st Century Problems. 1st Edn., CRC Press, Boca Raton, FL, ISBN-13: 9781420054910 , pp: 217.

Bottani, E., 2009. A fuzzy QFD approach to achieve agility. Int. J. Prod. Econ., 119: 380-391. DOI: 10.1016/j.ijpe.2009.02.013

Cho, H., M. Jung and M. Kim, 1996. Enabling technologies of agile manufacturing and its related activities in Korea. Comput. Ind. Eng., 30: 323-334. DOI: 10.1016/0360-8352(96)00001-0

Datta, S., 2006. Agility measurement index: A metric for the crossroads of software development methodologies. Proceedings of the 44th Annual Southeast Regional Conference, Mar. 10-12, ACM Press, Melbourne, Florida, pp: 271-273. DOI: 10.1145/1185448.1185509

DeLaurentis, D., 2005. Understanding transportation as system-of-systems design problem. Proceedings of the 43rd AIAA Aerospace Sciences Meeting and Exhibit, Jan. 10-13, Reno, NV, USA., pp: 14-14.

Dove, R., 1999. Knowledge management, response ability, and the agile enterprise. J. Knowl. Manag., 3: 18-35. DOI: 10.1108/13673279910259367
Dove, R., 2001. Response Ability: The Language, Structure and Culture of the Agile Enterprise. 1st Edn., John Wiley and Sons, Hoboken, NJ., ISBN13: 9780471350187, pp: 368.

Dove, R., 2004. Enterprise Agility-What is it and what Fuels http://www.parshift.com/Essays/essay065.htm

Dove, R., 2005a. Fundamental principles for agile systems engineering. Proceedings of the Conference on Systems Engineering Research, Mar. 23-25, SIT Press, Hoboken, NJ, pp: 1-12.

Dove, R., 2005b. Agile enterprise cornerstones: knowledge, values, and response ability. Bus. Agility Inform. Technol. Diff., 180: 313-330. DOI: 10.1007/0-387-25590-7 20

Fiksel, J., 2007. Sustainability and resilience: Toward a systems approach. IEEE Eng. Manag. Rev., 35: 5-5. DOI: 10.1109/EMR.2007.4296420

Fliedner, G. and R. Vokurka, 1997. Agility: Competitive weapon of the 1990s and beyond. Prod. Invent. Manag. J., 38: 19-24.

Ganguly, A., R. Nilchiani and J.V. Farr, 2009. Evaluating agility in corporate enterprises. Int. J. Prod. Econ., 118: 410-423. DOI: 10.1016/j.ijpe.2008.12.009

Gold-Bernstein, B. and W. Ruh, 2004. Enterprise Integration: The Essential Guide to Integration Solutions. 1st Edn., Addison-Wesley, Boston, MA, ISBN-13: 9780321223906, pp: 408.

Goldman, S.L., R.N. Nagel and K. Preiss, 1995. Agile Competitors and Virtual Organizations. 1st Edn., John Wiley and Sons, USA., ISBN: 9780471286509, pp: 414.

Goranson, T., 1999. The Agile Virtual Enterprise: Cases, Metrics, Tools. 1st Edn., Praeger, New York, ISBN-10: 9781567202649, pp: 288.

Gunasekaran, A., 1999. Agile manufacturing: A framework for research and development. Int. J. Prod. Econ., 62: 87-105. DOI: 10.1016/S09255273(98)00222-9

Hoek, R.I.V., A. Harrison and M. Christopher, 2001. Measuring agile capabilities in the supply chain. Int. J. Operat. Prod. Manag., 21: 126-148. DOI: 10.1108/01443570110358495

Kettunen, P., 2009. Adopting key lessons from agile manufacturing to agile software product development-a comparative study. Technovation, 29: 408-422. DOI: 10.1016/j.technovation.2008.10.003

Kidd, P.T., 1997. Agile enterprise strategy: A next generation manufacturing concept. IEE Colloq. Agile Manuf., DOI: 10.1049/ic:19971335 
Kosanke, K., F. Vernadat and M. Zelm, 1999. CIMOSA: Enterprise engineering and integration. Comput. Ind., 40: 83-97. DOI: 10.1016/S01663615(99)00016-0

Kumar, A. and J.A. Motwani, 1999. A methodology for assessing time-based competitive advantage of manufacturing firms. Int. J. Operat. Prod. Manag., 15: 36-53. DOI: 10.1108/01443579510080409

Lin, C.T., H. Chiu and P.Y. Chu, 2006. Agility index in the supply chain. Int. J. Prod. Econ., 100: 285-299. DOI: $10.1016 /$ j.ijpe.2004.11.013

Luskasik, S.J., 1998. Systems, systems of systems, and the education of engineers. Artif. Intel. Eng. Des. Anal. Manuf., 12: 55-60. DOI: 10.1017/S0890060498121078

Maier, M., 1998. Architecting principles for systemsof-systems. Syst. Eng., 1: 267-284. DOI: 10.1002/(SICI)1520-6858(1998)1:4<267::AIDSYS3 $>3.0 . C O ; 2-D$

Mansouri, M. and A. Mostashari, 2010. A systemic approach to governance in extended enterprise systems. Proceedings of the 4th Annual IEEE Systems Conference, Apr. 5-8, San Diego, CA, pp: 311-316. DOI: 10.1109/SYSTEMS.2010.5482432

Manthorpe, W.H.J., 1996. The emerging joint system of system: A systems engineering challenge and opportunity for APL. JHU APL Tech. Digest, 17: 305-310.

Markus, M.L., 2000. Paradigm shifts-E-business and business/systems integration. Comm. AIS, 4: 1-45.

Metes, G.S., J. Gundry and P. Bradish, 1998. Agile Networking: Competing Through the Internet and Intranets. 1st Edn., Prentice-Hall, NJ, ISBN-13: 9780137601257, pp: 253.

Metropolitan Transportation Authority, 2010. Public Transportation for the New York Region. http://www.mta.info/mta/network.htm

Overby, E., A. Bharadwaj and V. Sambamurthy, 2006. Enterprise agility and the enabling role of information technology. Eur. J. Inform. Syst., 15: 120-131. DOI: 10.1057/palgrave.ejis.3000600

Pinkston, J., 2001. The ins and outs: How EAI differs. EAI J., pp: 48-52.

Rouse, W.B., 2005. Enterprises as systems: Essential challenges and approaches to transformation. Syst. Eng., 8: 138-150. DOI: 10.1002/sys.20029
Sage, A.P. and C.D. Cuppan, 2001. On the systems engineering and management of systems of systems and federations of systems information. Inf. Knowl. Syst. Manag., 2: 325-345.

Sanchez, L.M. and R. Nagi, 2001. A review of agile manufacturing systems. Int. J. Prod. Res., 39: 3561-3600. DOI: 10.1080/00207540110068790

Sharifi, H. and Z. Zhang, 1999. A methodology for achieving agility in manufacturing organizations: An introduction. Int. J. Prod. Econ., 62: 7-22. DOI: 10.1016/S0925-5273(98)00217-5

Sherehiy, B., W. Karwowski and J.K. Layer, 2007. A review of enterprise agility: Concepts, frameworks, and attributes. Int. J. Ind. Ergon., 37: 445-460. DOI: $10.1016 /$ j.ergon.2007.01.007

Slade, A.J. and A.F. Bokma, 2002. Ontologies within extended enterprises. Proceedings of the 35th Annual Hawaii International Conference on System Sciences, Jan. 7-10, IEEE Press, Honolulu, Hawaii, pp: 541-550. DOI: 10.1109/HICSS.2002.993934

Tan, W.A.X., J.S. and J.L. Wang, 2006. A serviceoriented virtual enterprise architecture and its applications in Chinese tobacco industrial sector. Proceedings of the IEEE International Conference on e-Business Engineering, Oct. 2006, Shanghai, China, pp: 95-101. DOI: 10.1109/ICEBE.2006.13

Tillquist, J., 2002. Strategic connectivity in extended enterprise networks. J. Elect. Comm. Res., 3: 77-85.

Tsourveloudis, N.C. and K.P. Valavanis, 2001. On the measurement of enterprise agility. J. Intel. Robot. Syst., 33: 329-342. DOI: 10.1023/A:1015096909316

Yang, S.L. and T.F. Li, 2002. Agility evaluation of mass customization product manufacturing. J. Mater. Process. Technol., 129: 640-644. DOI: 10.1016/S0924-0136(02)00674-X

Yu, L. and Z. Heng, 2006. Measuring agility of enterprise using analytic hierarchy process and bayesian belief networks. Proceedings of the International Conference on Management Science and Engineering, Oct. 5-7, Lille, China, pp: 551-556. DOI: 10.1109/ICMSE.2006.313954

Yusuf, Y.Y., M. Sarhadi and A. Gunasekaran, 1999. Agile manufacturing:: The drivers, concepts and attributes. Int. J. Prod. Econ., 62: 33-43. DOI: 10.1016/S0925-5273(98)00219-9 